\title{
Temporal and Spatial Characteristics of Summer Extreme Precipitation in Eastern China and Possible Causalities
}

\author{
Yahan Zhong, Mengzhou Yang, Chaoxia Yuan*
}

Key Laboratory of Meteorological Disaster of Ministry of Education, Collaborative Innovation Center on Forecast and Evaluation of Meteorological Disasters, Nanjing University of Information Science \& Technology, Nanjing, China

Email: *chaoxia.yuan@nuist.edu.cn

How to cite this paper: Zhong, Y. H., Yang, M. Z., \& Yuan, C. X. (2020). Temporal and Spatial Characteristics of Summer Extreme Precipitation in Eastern China and Possible Causalities. Journal of Geoscience and Environment Protection, 8, 36-46.

https://doi.org/10.4236/gep.2020.86004

Received: May 25, 2020

Accepted: June 25, 2020

Published: June 28, 2020

Copyright $\odot 2020$ by author(s) and Scientific Research Publishing Inc. This work is licensed under the Creative Commons Attribution International License (CC BY 4.0).

http://creativecommons.org/licenses/by/4.0/

(c) (i) Open Access

\begin{abstract}
In the past decades, with the increasing frequency of extreme weather and climate events, the world has suffered huge losses. Based on NCEP/NCAR reanalysis data and China regional precipitation data provided by China $\mathrm{Me}-$ teorological Administration, the extreme precipitation events in eastern China are defined by relative threshold method, and the temporal and spatial characteristics of summer extreme precipitation in eastern China from 1961 to 2016 are analyzed by empirical orthogonal function (EOF), and the reverse distribution of extreme precipitation in the middle and lower reaches of the Yangtze River and south China by Indian Ocean warm pool is revealed influence. The results show that the total amount and frequency of extreme precipitation in summer are concentrated in the Yangtze River Basin and south China. EOF1 decomposition of extreme precipitation reflects the interannual oscillation characteristics of reverse spatial distribution in the Yangtze River Basin and south China. The time series corresponding to EOF1 has significant interannual characteristics. The Pacific-Japan (PJ) teleconnection pattern is a circulation system that significantly affects the spatial-temporal pattern of extreme precipitation in southern China. When the PJ pattern is in the positive phase, the anticyclone controls the south China region, and restrains the convective activity, which results in the decrease of extreme precipitation. The anomalous southwest wind to the south of $30^{\circ} \mathrm{N}$ and the anomalous northerly wind to the north of $30^{\circ} \mathrm{N}$ converge in the middle and lower reaches of the Yangtze River. Combining with the sufficient water vapor carried by the anomalous southwest airflow at the edge of anticyclone, it is more conducive to the formation of extreme precipitation. The east propagating Kelvin wave in the warm pool of the Indian Ocean is an important reason for the formation of the PJ pattern and finally the formation of extreme precipi-
\end{abstract}


tation anomalies in China.

\section{Keywords}

Extreme Precipitation, Pacific-Japan Pattern, Indian Ocean Warm Pool

\section{Introduction}

The fifth assessment report (AR5) of the first working group of the Intergovernmental Panel on Climate Change (IPCC) introduces and analyzes an unprecedented global climate change process in the earth system, which is characterized by global warming. Global warming is first manifested in the sharp rise of global surface temperature, which has a significant and far-reaching impact on the global climate system, not only in the rise of global sea surface temperature (SST) and global sea level, but also in the significant increase in the frequency and intensity of global extreme weather and climate events (Zhai et al., 2005).

In the past few decades, with the increasing frequency of extreme weather and climate events, with the continuous development of human society and economy, human beings are facing increasing losses of extreme natural disasters. East China is located in the East Asian monsoon region. Influenced by the East Asian summer monsoon, extreme weather and climate events occur almost every year, especially extreme precipitation. Extreme precipitation has become one of the important factors restricting the sustainable development of social economy in China. Therefore, it is an urgent need to carry out in-depth research on extreme precipitation events, comprehensively grasp the detection methods and spatial-temporal distribution characteristics of extreme precipitation events, and then analyze the physical mechanism of extreme precipitation events, which is of great practical significance.

The characteristics of extreme precipitation in China have been widely studied. In the past few decades, China's total precipitation has not changed much; the precipitation frequency is decreasing, but the intensity is increasing, and the regional and seasonal differences are very large (Wu et al., 2015). Most scholars use the absolute threshold to divide the precipitation into different levels of precipitation events. There are still many disputes about the trend of precipitation in China. For example, many studies show that the winter precipitation in northeast China is decreasing (Wang \& Yan, 2009; Hu et al., 2003), but some studies also find that the winter precipitation in this area is increasing (Liu et al., 2005). Xu et al. (2011) showed that the total amount of extreme precipitation increased significantly in the lower and middle reaches of the Yangtze River and the northwest of China, but the increasing trend was smaller in the north and northeast of China. The different results of these studies show that the spatial and temporal variation of precipitation is very different, so it is necessary to fur- 
ther study the precipitation variation in different regions and seasons.

Eastern China is located in the East Asian summer monsoon region, which contains complex dynamic, thermal and hydrological processes (Wang \& Lin, 2002; Ding \& Johnny, 2005). The annual total precipitation is concentrated in summer, and there is a close relationship between summer precipitation and extreme precipitation. Many scholars have done a lot of work to reveal the precipitation anomaly in the East, and found that there is a relationship between the precipitation anomaly in the east and the intensity of the East Asian summer monsoon. As a member of the East Asian summer monsoon system, the subtropical high in the Northwest Pacific has also attracted a lot of attention. It has been found that the short-term changes of the shape and location of the subtropical high in the Northwest Pacific in summer and the seasonal advance and retreat significantly affect the occurrence of regional extreme precipitation in China. In addition, the study of Wang and Zhou (2005) found that the summer circulation in East Asia has a significant impact on the extreme precipitation in China. As an important forcing source, the tropical SST in summer plays a leading role in the large-scale circulation anomaly. The Pacific SST anomaly (Wang et al., 2000; Wang et al., 2003) and the Indian Ocean warm pool (Wu et al., 2010) are important factors affecting the large-scale circulation anomaly in East Asia. Wu et al. (2010) pointed out that the anomalous anticyclone in the Western Pacific was caused by the cold SST anomaly in the Northwest Pacific and the warming of the Indian Ocean basin. However, from June to August, the former was weakening while the latter was gradually increasing. The anomalous anticyclone in the Western Pacific may further stimulate the PJ pattern in summer to the north, which leads to the North-South inverse oscillation of the atmospheric circulation anomalies in the Philippines and the vicinity of mid latitude Japan through the anomalous meridional circulation (Li et al., 2017).

Previous studies on extreme precipitation have done a lot of work, but in terms of China's extreme precipitation research, the research area is mainly Jianghuai and south China, and the research on extreme precipitation in other areas is relatively small. In the past, the research on extreme precipitation was mostly focused on individual cases, and focused on the temporal and spatial distribution of extreme precipitation and its response to climate warming.

Based on the conventional reanalysis data, the temporal and spatial pattern of summer extreme precipitation in eastern China and the influence of Tropical Indian Ocean on the summer reverse interannual oscillations in the middle and lower reaches of the Yangtze River and south China are studied in this paper. The rest of the article is arranged as follows. The second chapter briefly introduces the data and methods used. The third chapter focuses on the temporal and spatial characteristics of extreme precipitation. The fourth chapter analyzes the main causes of the extreme precipitation anomalies in the eastern part of China from the perspective of the tropical Indian Ocean Warm Pool affecting the PJ pattern and thus affecting the summer extreme precipitation in eastern China. 
The fifth chapter is the summary and discussion of the whole paper.

\section{Data and Methods}

The data of precipitation in China in this study comes from the daily grid data of China's surface precipitation provided by China Meteorological Data Network (https://data.cma.cn/site/index.html), with a time span of 1961-2016 and a horizontal resolution of $0.5^{\circ} \times 0.5^{\circ}$. The data set has been integrated daily precipitation of 2474 meteorological stations in mainland China. In order to facilitate the data processing, the precipitation on February 29 of all leap years is eliminated artificially. In addition, the NCEP/NCAR monthly reanalysis data set (Kalnay et al., 1996) is also used in this study. The monthly mean precipitation data of Global Precipitation Climate Center (GPCC) is used in the analysis of large-scale precipitation anomalies, and the resolution is $1^{\circ} \times 1^{\circ}$. The National Oceanic and Atmospheric Administration (NOAA) extended reconstructed sea surface temperature V5 (Huang et al., 2017) for the same period are also used.

The main methods used in this study are relative threshold method, EOF analysis, PJ index.

In this paper, the relative threshold method is used to define the extreme precipitation events at a single point, with 1961-2016 as the base period. The calculation steps of the extreme threshold method are as follows: firstly, according to the national precipitation data, the time series of daily maximum temperature in summer in the reference period of a grid point is arranged from small to large, and then the $95^{\text {th }}$ percentile of the series is taken as the extreme precipitation threshold value of the grid point. When the daily precipitation of this grid point is greater than the threshold value of this grid point, the daily precipitation of this grid point is defined as the extreme precipitation of this process. The frequency and precipitation involved in this paper are 92 days in summer every year.

In addition, EOF is used to analyze the temporal and spatial distribution characteristics of summer extreme precipitation in eastern China. The PJ index is used to study the relationship between the P-J pattern and the extreme precipitation in eastern China. The definition of the PJ index follows Nitta (1987), only changing the cloud amount to the more commonly used and widely accepted precipitation:

$$
\begin{gathered}
\mathrm{PJ} \text { index }=\mathrm{C} 1-\mathrm{C} 2 \\
\mathrm{C} 1\left(16^{\circ} \mathrm{N}-20^{\circ} \mathrm{N}, 142^{\circ} \mathrm{E}-150^{\circ} \mathrm{E}\right) \\
\mathrm{C} 2\left(32^{\circ} \mathrm{N}-38^{\circ} \mathrm{N}, 134^{\circ} \mathrm{E}-142^{\circ} \mathrm{E}\right)
\end{gathered}
$$

Where $\mathrm{C}(\mathrm{A}, \mathrm{B})$ is the summer mean value of precipitation in latitude range $\mathrm{A}$ and longitude range $B$.

\section{Temporal and Spatial Distribution of Summer Extreme Precipitation Frequency in Eastern China}

After eliminating the number of days without precipitation, the overall sequence 
is sorted. The threshold value of summer extreme precipitation is obtained by the relative threshold method, and the spatial distribution of the threshold value of summer extreme precipitation is plotted, as shown in Figure 1(a). The results show that the spatial distribution of the threshold value of summer extreme precipitation in China is significantly different, and the threshold value of extreme precipitation decreases from southeast to northwest. In addition to the coastal areas, the extreme precipitation threshold near Wuhan is also an obvious large value area. In addition, considering altitude and climate characteristics, it is not difficult to find that the size of extreme precipitation threshold in the north is closely related to altitude. For example, in north China, there is an obvious feature of low in the west and high in the east near $35^{\circ} \mathrm{N}$, and there is a significant difference in climate characteristics between the east and the west of Taihang Mountains, mainly because the west of Taihang Mountains is the Loess Plateau area, while the east of Taihang mountains is the North China Plain.

Figure 1(b) shows the multi-year average spatial distribution of summer extreme precipitation. The spatial distribution of summer extreme precipitation in the east is similar to the spatial distribution of extreme precipitation threshold, showing the spatial distribution characteristics of more in the south and less in the north, more in the east and less in the west. The large value center is mainly located in the coastal areas of Guangdong Province. In addition, another significant large value center in the south of China lies in the Yangtze River Basin and Ganjiang River Basin, which has obvious relationship with altitude and climate type. The northern coastal area of China belongs to the subtropical monsoon region. In summer, affected by the warm and humid air flow in the south, the total amount of extreme precipitation is significantly more than that in the inland. Especially, the summer extreme precipitation of Liaodong Peninsula near $40^{\circ} \mathrm{N}$ is also about $200 \mathrm{~mm}$, which is the same as that in most of the southern sub regions

(a) Threshold of EC extreme precipitation

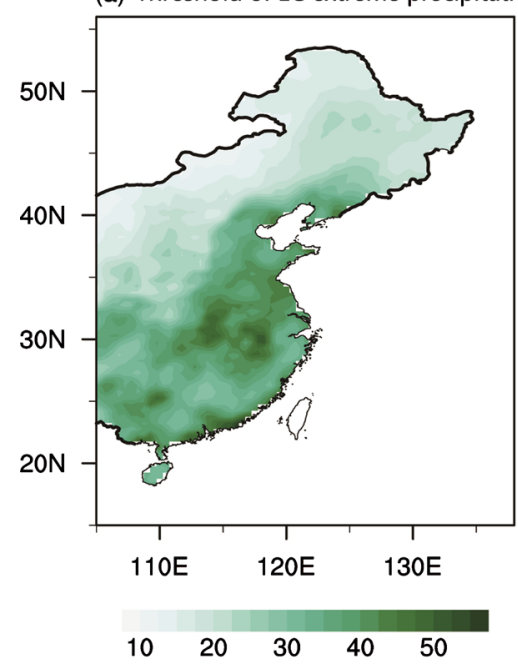

(b) EC extreme precipitation

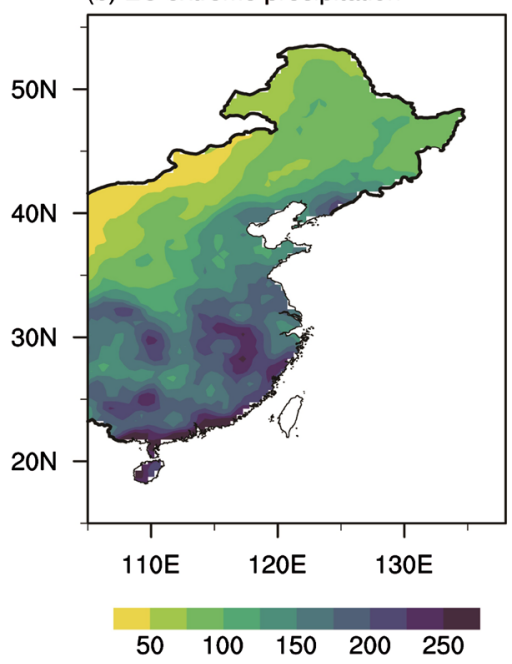

(c) Variance of EC extreme precipitation

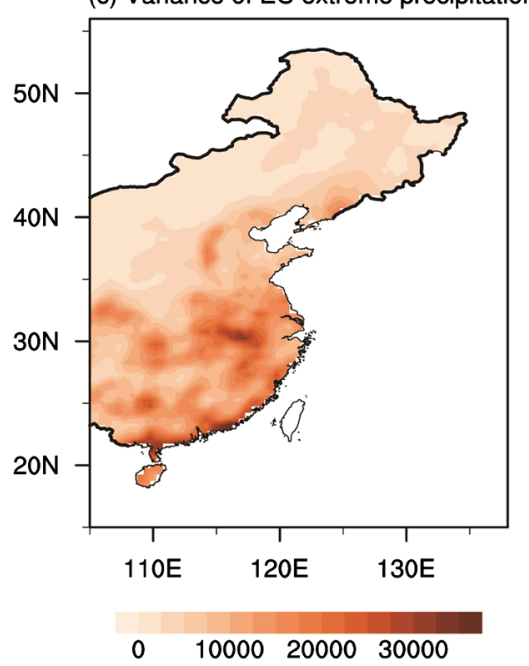

Figure 1. (a) Spatial distribution of summer extreme precipitation thresholds in eastern China (shading, mm). (b) Annual average spatial distribution of summer extreme precipitation in eastern China (shading, $\mathrm{mm}$ ). (c) Spatial distribution of summer extreme precipitation variance in eastern China (shading, $\mathrm{mm}^{2}$ ). 
south of $30^{\circ} \mathrm{N}$.

It can be seen from the spatial distribution diagram of variance of summer extreme precipitation (Figure 1(c)) that the spatial distribution of summer extreme precipitation change in eastern China is very similar to that of summer extreme precipitation and extreme precipitation threshold, and also shows the spatial distribution characteristics of more in the south and less in the north, more in the east and less in the west.

In order to analyze the temporal and spatial distribution characteristics of summer extreme precipitation in eastern China, EOF analysis is carried out in this study. The first mock exam is north test, and variance is interpreted as $11.62 \%$. The first EOF mode (EOF1) shows the spatial distribution of the north and south in the south of China. As shown in Figure 2(a), there is also spatial distribution of east and west in the northeast China. However, because of the great difference in the total precipitation between the north and the south, the extreme precipitation in the north is very small compared with the extreme precipitation in the south. The time series of EOF1 (Figure 2(b)) mainly reflects the interannual variability of summer extreme precipitation in eastern China.

\section{The Influence of Warm Pool in Indian Ocean on Summer Extreme Precipitation in Eastern China}

In order to further clarify the possible causes of the inverse change of extreme precipitation in the middle and lower reaches of the Yangtze River and south China, we analyzed the large-scale circulation and SST anomalies associated with it. Previous studies have shown that there is a close relationship between precipitation anomalies and large-scale circulation anomalies. Therefore, this study analyzes the large-scale circulation anomalies and precipitation anomalies in the

(a) EOF1

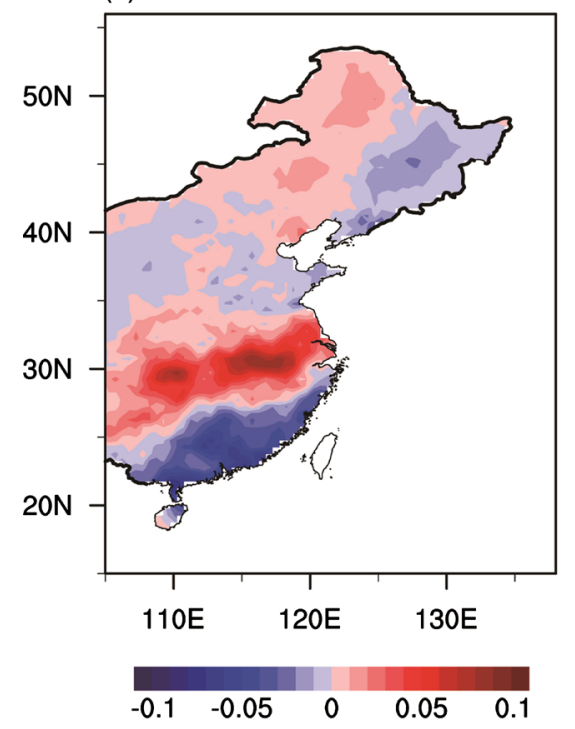

(b) PC1

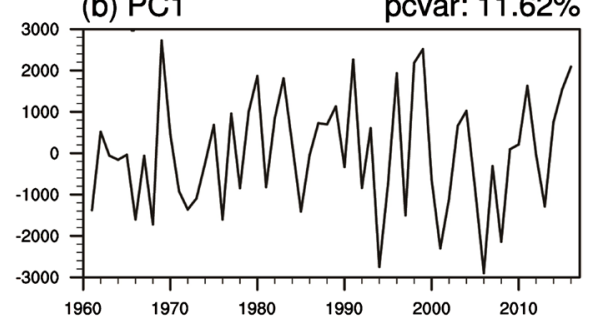

Figure 2. (a) The first EOF modes and (b) time series of the summer extreme precipitation in east China. 
Northwest Pacific associated with extreme precipitation anomalies. As shown in Figure 3(a), there is an obvious anticyclone anomaly in the $20^{\circ} \mathrm{N}$ Northwest Pacific region, extending westward to the bay of Bengal. To the north of anticyclone anomaly, cyclonic circulation anomaly appears. The two circulation anomaly structures in the Northwest Pacific are very similar to the PJ pattern. The anomalous anticyclone in the lower layer controls the south China area, and the inner part is the abnormal sinking movement, which restrains the convective activity and thus restrains the precipitation in the south China area. The decrease of precipitation will inevitably lead to the decrease of extreme precipitation. The edge area of the anticyclone is the southwest air flow, which transports more water vapor from the South China Sea and the bay of Bengal to the middle and lower reaches of the Yangtze River, providing sufficient water vapor conditions. The abnormal southwest wind to the south of $30^{\circ} \mathrm{N}$ and the abnormal northerly wind to the north of $30^{\circ} \mathrm{N}$ converge in the middle and lower reaches of the Yangtze River. Therefore, the circulation characteristics of PJ pattern are directly related to the decrease of extreme precipitation in south China and the increase of extreme precipitation in the middle and lower reaches of the Yangtze River.

The PC1 and PJ indexes of extreme precipitation are transformed by fast Fourier transform, and the interannual component less than 10 years is retained.

(a) $850 \mathrm{hPa}$ Vort \& Precip reg onto ECSEP

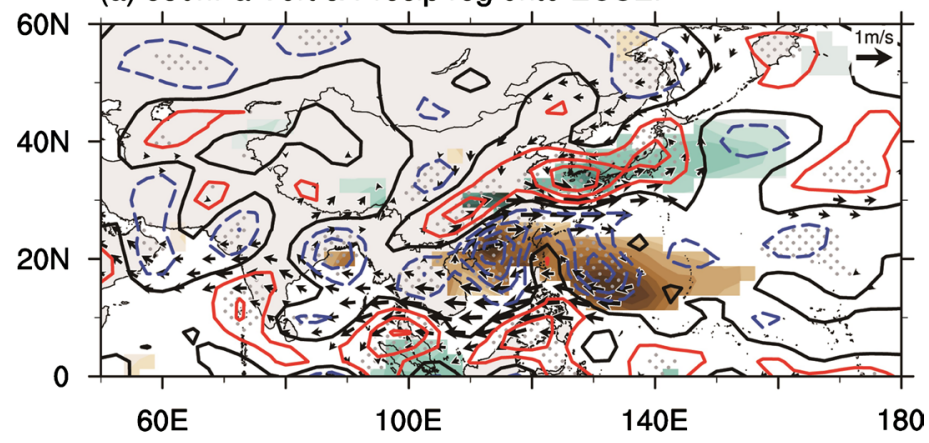

(b) $850 \mathrm{hPa}$ Vort \& Precip reg onto PJI

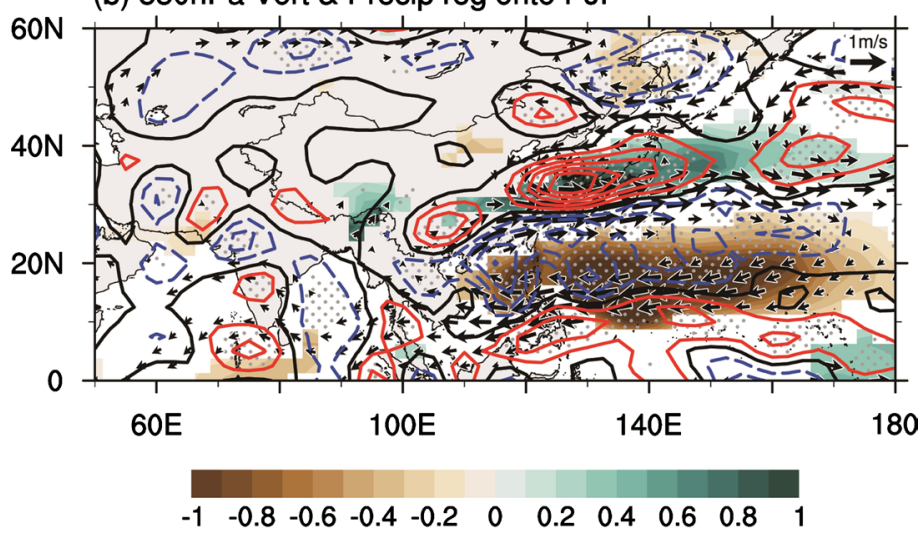

Figure 3. Summer anomalies of vorticity (contour, int: $4 \times 10^{-7} \mathrm{~s}^{-1}$ ), wind field (vector, $\mathrm{m}$ $\mathrm{s}^{-1}$ ) and precipitation (shading, $\mathrm{mm}$ month $^{-1}$ ) regressed on the time sequences of (a) EOF1 and (b) PJ index. The anomalies significant at the 95\% confidence level invorticity and wind are shown only and in precipitation are stippled. 
After standardization, the correlation coefficient of 56-year time series is as high as 0.48 (Figure 4), passing the significance test with $99 \%$ reliability. In order to be closer to the general expression habit, we multiply the index by negative one. Therefore, the following figures all reflect the connection between the PJ pattern of positive phase and the spatial-temporal distribution pattern of summer rainfall in the south of China. When PJ pattern with positive phase appears, the extreme precipitation in the middle and lower reaches of the Yangtze River appears positive anomaly, and the extreme precipitation in South China appears negative anomaly (Figure $3(\mathrm{~b})$ ).

The anomalies of large-scale circulation and precipitation in East Asia usually do not exist in isolation. There is a strong east wind anomaly near $10^{\circ} \mathrm{N}$ on 850 $\mathrm{hPa}$ (Figure 3), which extends all the way to the North Indian Ocean. It is considered that the Kelvin wave response may be caused by the warm SST anomaly in the Indian Ocean. In order to verify the relationship between SST anomalies and the inverse distribution of precipitation in the middle and lower reaches of the Yangtze River and south China, we use extreme precipitation PC1 series and PJ index to regress the Global SST anomalies, and find that the most significant and direct signals are the warm SST anomalies in the Indian Ocean and the cold SST anomalies near Japan, as shown in Figure 5(a) and Figure 5(b).

A large number of studies have shown that the Indian Ocean Warm Pool forces the atmosphere to form an abnormal upward movement, which is conducive to the formation of convective activities, so there is a positive precipitation anomaly in the Indian Ocean. In addition, the Indian Ocean warm pool formed an anomalous anticyclone in the Northwest Pacific by stimulating the eastward Kelvin wave, which is consistent with the gill response of the atmosphere to the non adiabatic heating of the heat source. The area controlled by the abnormal anticyclone is the downdraft, which restrains the convective activity and leads to the decrease of precipitation. Therefore, the negative precipitation anomaly appears in the Northwest Pacific. At the same time, the anticyclone anomaly further stimulates the cyclone circulation anomaly northward through the abnormal Hadley circulation, and forms and maintains the abnormal cold SST and

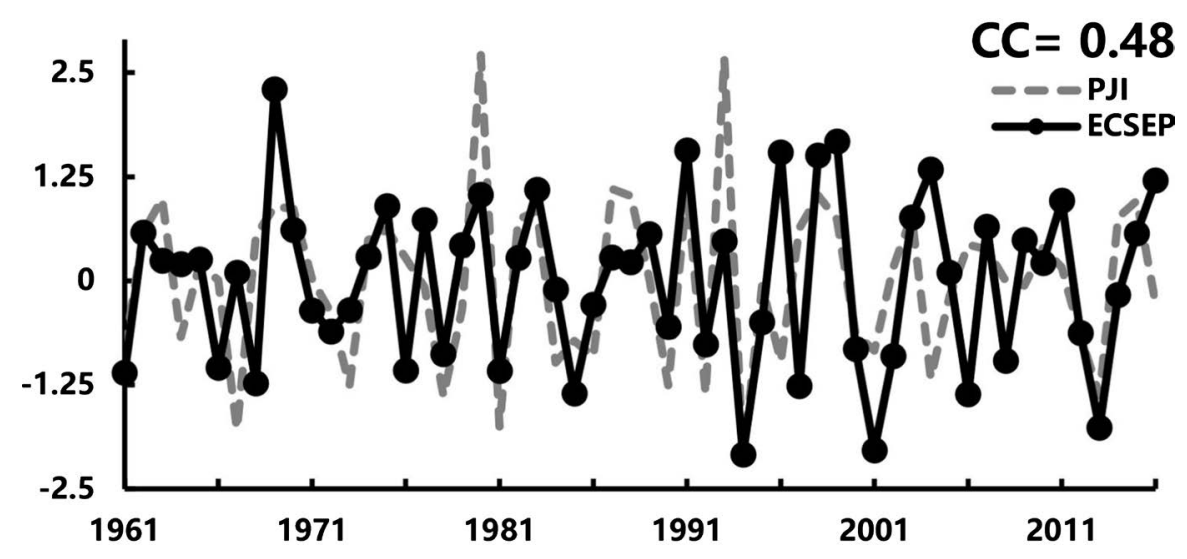

Figure 4. Time series of (a) EOF1 (black line) and (b) PJ index (grey line). 
(a) $500 \mathrm{hPa}$ StmFunc \& SST reg onto ECSEP

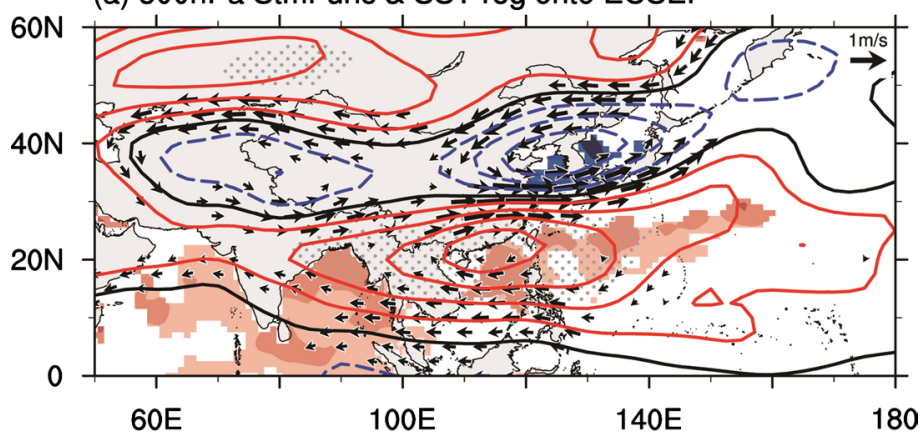

(b) $500 \mathrm{hPa}$ StmFunc \& SST reg onto PJI

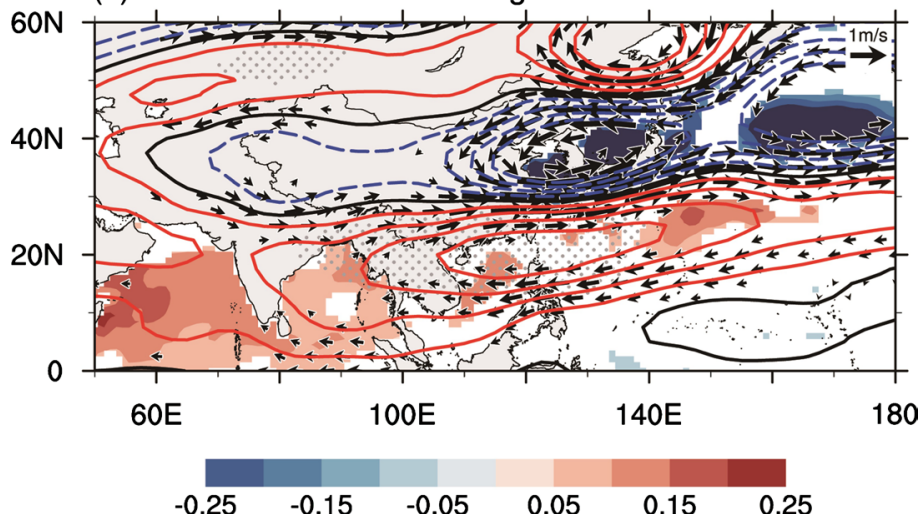

Figure 5. Summer anomalies of streamfunction (contour, int: $2 \times 10^{-5} \mathrm{~m}^{2} \mathrm{~s}^{-1}$ ) and SST (shading, ${ }^{\circ} \mathrm{C}$ ) regressed on the time sequences of (a) EOF1 and (b) PJ index. The anomalies significant at the $95 \%$ confidence level instream function are shown only and in SST are stippled.

positive precipitation anomaly near the abnormal cyclone through the sea air interaction. Circulation anomaly and precipitation anomaly are important marks of PJ pattern, while Indian Ocean warm pool is the key to trigger PJ pattern.

\section{Conclusion}

This paper focuses on the temporal and spatial characteristics of summer extreme precipitation in eastern China. It is found that the total amount and frequency of summer extreme precipitation are concentrated in the south of China. EOF1 reflects the characteristics of reverse interannual oscillation in the middle and lower reaches of the Yangtze River and southern China, and has significant interannual characteristics. In this study, the characteristics of reverse interannual oscillations in the middle and lower reaches of the Yangtze River and south China are diagnosed and attributed, and the influence of the Indian Ocean warm pool on the reverse distribution of the middle and lower reaches of the Yangtze River and south China by activating the PJ pattern is revealed. The PJ pattern has a significant and direct impact on the temporal and spatial pattern of extreme precipitation in eastern China. The Indian Ocean warm pool formed the anticyclone anomaly in the Northwest Pacific by stimulating the Kelvin wave from the east. Combined with the convection near the Philippines, the anticyc- 
lone circulation was further stimulated northward through the Hadley circulation, and the abnormal cold sea temperature and positive precipitation anomaly near the abnormal cyclone were formed and maintained through the air sea interaction. When the PJ pattern is in the positive phase, the anticyclone controls the south China region and restrains the convective activity, resulting in the decrease of extreme precipitation. The anomalous southwest wind to the south of $30^{\circ} \mathrm{N}$ and the anomalous northerly wind to the north of $30^{\circ} \mathrm{N}$ converge in the middle and lower reaches of the Yangtze River. Combined with the sufficient water vapor carried by the anomalous southwest airflow at the edge of the anticyclone, it is more conducive to the formation of extreme precipitation, which results in the reverse distribution characteristics of the middle and lower reaches of the Yangtze River and south China.

\section{Acknowledgements}

The authors are very thankful to the three reviewers for their constructive comments that help improve the research greatly. The research is supported by the National Key R\&D Program of China 2016YFA0600402 and 2016YFA0600702, National Natural Science Foundation of China 41875099, and the funding of Jiangsu innovation \& entrepreneurship team.

\section{Conflicts of Interest}

The authors declare no conflicts of interest regarding the publication of this paper.

\section{References}

Ding, Y. H., \& Johnny, C. L. (2005). The East Asian Summer Monsoon: An Overview. Meteorology and Atmospheric Physics, 89, 117-142. https://doi.org/10.1007/s00703-005-0125-z

Hu, Z. Z., Yang, S., \& Wu, R. (2003). Long-Term Climate Variations in China and Global Warming Signals. Journal of Geophysical Research, 108, 4614. https://doi.org/10.1029/2003JD003651

Huang, B., Thorne, P. W., Banzon, V. F., Boyer, T., Chepurin, G., Lawrimore, J. H., \& Zhang, H. M. (2017). NOAA Extended Reconstructed Sea Surface Temperature (ERSST), Version 5. NOAA National Centers for Environmental Information.

Kalnay, E., Kanamitsu, M. et al. (1996). The NCEP/NCAR 40-Year Reanalysis Project. Bulletin of the American Meteorological Society, 77, 437-470. https://doi.org/10.1175/1520-0477(1996)077<0437:TNYRP>2.0.CO;2

Li, T., Li, T., Ke, Y. H., \& Zhao, J. W. (2017). Causes of Interannual and Interdecadal Variations of the Summertime Pacific-Japan-Like Pattern over East Asia. Journal of Climate, 30, 8845-8864. https://doi.org/10.1175/JCLI-D-15-0817.1

Liu, B. H., Xu, M., Henderson, M., \& Qi, Y. (2005). Observed Trends of Precipitation Amount, Frequency, and Intensity in China, 1960-2000. Journal of Geophysical Research, 110, D08103. https://doi.org/10.1029/2004JD004864

Nitta, T. (1987). Convective Activities in the Tropical Western Pacific and Their Impact on the Northern Hemisphere Summer Circulation. Journal of the Meteorological So- 
ciety of Japan, 65, 373-390. https://doi.org/10.2151/jmsj1965.65.3_373

Wang, B., \& Lin, H. (2002). Rainy Season of the Asian-Pacific Summer Monsoon. Journal of Climate, $15,386-398$. https://doi.org/10.1175/1520-0442(2002)015<0386:RSOTAP>2.0.CO;2

Wang, B., Steven, C. C., \& Liu, P. (2003). Contrasting the Indian and East Asian Monsoons: Implications on Geologic Timescales. Marine Geology, 201, 5-21. https://doi.org/10.1016/S0025-3227(03)00196-8

Wang, B., Wu, R. G., \& Fu, X. H. (2000). Pacific-East Asian Teleconnection: How Does ENSO Affect East Asian Climate? Journal of Climate, 13, 1517-1536. https://doi.org/10.1175/1520-0442(2000)013<1517:PEATHD>2.0.CO;2

Wang, Y. Q., \& Yan, Z. (2009). Trends in Seasonal Precipitation over China during 1961-2007. Atmospheric and Oceanic Science Letters, 2, 165-171. https://doi.org/10.1080/16742834.2009.11446798

Wang, Y. Q., \& Zhou, L. (2005). Observed Trends in Extreme Precipitation Events in China during 1961-2001 and the Associated Changes in Large-Scale Circulation. Geophysical Research Letters, 32, L09707. https://doi.org/10.1029/2005GL023769

Wu, B., Li, T., \& Zhou, T. J. (2010). Relative Contributions of the Indian Ocean and Local SST Anomalies to the Maintenance of the Western North Pacific Anomalous Anticyclone during the El Niño Decaying Summer. Journal of Climate, 23, 2974-2986. https://doi.org/10.1175/2010JCLI3300.1

$\mathrm{Wu}, \mathrm{Y}$., Wu, S., Wen, J. et al. (2015). Changing Characteristics of Precipitation in China during 1960-2012. International Journal of Climatology, 36, 1387-1402. https://doi.org/10.1002/joc.4432

Xu, X., Du, Y. G., Tang, J., \& Wang, Y. (2011). Variations of Temperature and Precipitation Extremes in Recent Two Decades over China. Atmospheric Research, 101, 143-154. https://doi.org/10.1016/j.atmosres.2011.02.003

Zhai, P., Zhang, X., Wan, H. et al. (2005). Trends in Total Precipitation and Frequency of Daily Precipitation Extremes over China. Journal of Climate, 18, 1096-1108.

https://doi.org/10.1175/JCLI-3318.1 